\title{
Foreign and Domestic Uncertainty Shocks in Four Open Economies
}

\author{
Rachatar Nilavongse ${ }^{1,2}$ (D) Michał Rubaszek ${ }^{3} \cdot$ Karsten Staehr $^{1,4}$. \\ Gazi Salah Uddin ${ }^{2}$
}

Accepted: 2 December 2021 / Published online: 21 December 2021

(c) The Author(s), under exclusive licence to Springer Science+Business Media, LLC, part of Springer Nature 2021

\begin{abstract}
This paper investigates how the economic performance of four economies with floating exchange rates is affected by shocks in domestic and US economic policy uncertainty. We estimate a Bayesian VAR model describing the dynamics of ten local and US variables for each of the four countries and use it to evaluate the response of the system to structural shocks. The analysis reveals that increased economic uncertainty in the US reduces industrial output in all the countries analysed, while the effect of increased domestic uncertainty varies across the economies. A key finding concerns the role of the exchange rate. Whereas the real effective exchange rate amplifies the effect of uncertainty shocks in the US, it typically helps absorb shocks in the open economies. This asymmetry may reflect the role of the US as a safe haven in times of increased uncertainty.
\end{abstract}

Keywords Economic policy uncertainty $\cdot$ Foreign and domestic shocks $\cdot$ Real exchange rate

JEL Classification $\mathrm{C} 1 \cdot \mathrm{E} 2 \cdot \mathrm{F} 2$

\section{Introduction}

Uncertainty about future economic developments and policies is unavoidable and can influence macroeconomic developments in profound ways (Jurado et al. 2015; Baker et al. 2016). Local uncertainty may influence economic performance through

Rachatar Nilavongse

rachatar.nilavongse@taltech.ee

1 Department of Economics and Finance, Tallinn University of Technology, Tallinn, Estonia

2 Department of Management and Engineering, Linköping University, Linköping, Sweden

3 Collegium of Economic Analysis, SGH Warsaw School of Economics, Warsaw, Poland

4 Bank of Estonia, Tallinn, Estonia 
private decisions about consumption, investment and capital flows, but it may also affect the economy indirectly through changes in various economic policies. The effects of global economic uncertainty can equally be further amplified through various channels that transmit across countries.

The crisis that started with the Covid-19 pandemic is one example of how uncertainty about the economic outlook and about the policies taken to combat events like a pandemic and a resulting economic downturn may prove important for the dynamics of an economy. Uncertainty about future economic developments can shoot up during crises or major economic and political events, but changes in uncertainty can also happen without any apparent cause.

Since open economies are affected by both foreign and domestic shocks, it is important for policymakers to understand how the domestic economy may be affected by uncertainty shocks that originate at home and those from abroad. Monetary authorities, for instance, would benefit from knowing how shifts in global and local uncertainty affect exchange rates and the dynamics of inflation. Such analysis would be also informative for international investors, who must assess the returns and risks in various markets.

Quantifying uncertainty is a complex matter, and the economics literature has produced numerous measures or proxies of economic uncertainty (see the discussion in Jurado et al. 2015). One of the more frequently used measures is the Economic Policy Uncertainty (EPU) index documented in Baker et al. (2016). Various versions of the EPU index have been produced, but the original one, which is used in this paper, is based entirely on extracts of words from articles in major newspapers in the country analysed. The index is not derived from macroeconomic or financial variables and so it may be seen as a subjective measure of economic uncertainty in the economy.

Several papers have examined the effects of uncertainty shocks for the US economy or the economy of a selected country (Jurado et al. 2015; Baker et al. 2016; Caldara et al. 2016; Basu and Bundick 2017). These studies usually apply a structural vector autoregressive (VAR) framework and typically find that an unexpected rise in uncertainty has a negative impact on real economic activity. These papers do not however consider how uncertainty shocks affect exchange rate movements.

Another group of studies have analysed the effects of global economic uncertainty shocks on local economies, also typically using the structural VAR methodology. An early study by Colombo (2013) examines the spillovers from US EPU disturbances to the euro area economy. In the same vein, Stockhammar and Österholm (2016) investigate the effect of US EPU shocks on the Swedish economy, while Stockhammar and Österholm (2017) extend the analysis to nine small, open economies. However, these papers do not consider domestic EPU shocks and do not include exchange rate movements in the model specification.

There are also articles that explore the role of global and local uncertainty shocks, but focus only on a single country. Cheng (2017) for example investigates how foreign and domestic EPU shocks affect the dynamics of the South Korean economy, including the real effective exchange rate. Nilavongse et al. (2020) meanwhile analyse the effects of EPU shocks on UK macroeconomic variables, including the exchange rate of the British pound. Given that these studies have a single-country 
focus though, it is difficult to assess how far the main findings can be generalised for a larger group of economies.

This paper adds to this discussion by analysing and comparing the macroeconomic effects of domestic and foreign uncertainty shocks in four open economies with floating exchange rates, i.e. Canada, South Korea, Sweden and the UK. Our selection of countries is based on three criteria: they are developed countries, they have a floating exchange rate, and the EPU series are available for them. ${ }^{1}$ The economies of the countries are relatively small, but exhibit sizeable foreign trade and cross-border financial flows.

For each country, we estimate and simulate a structural Bayesian VAR model that describes the dynamics of five local macroeconomic variables and five US ones. This allows us to address three questions. First, is the effect of a US EPU shock on the domestic economy the same across the countries? Second, what is the macroeconomic response to domestic EPU shocks? Third, are global or domestic EPU shocks more important for macroeconomic dynamics? Our focus is predominantly on real economic activity, but we also consider the dynamics of prices, interest rates and real exchange rates.

The paper contributes in a number of ways to the growing literature on how uncertainty or sentiment shocks affect macroeconomic performance. First, spillovers of economic uncertainty shocks have often been analysed using models that describe the dynamics of an individual economy (Stockhammar and Österholm 2016; Cheng 2017; Bakkar et al. 2021), while our study considers four open economies, so the results can be compared across the countries. Second, we use a relatively large VAR model that provides a detailed description of the local and US economies relative to the smaller VAR models typically used in other studies (Stockhammar and Österholm 2016, 2017). Third, we analyse in detail the role of the exchange rate as a mechanism for adjusting to economic uncertainty shocks. Finally, we provide the results of variance decompositions, which are a gauge for the quantitative importance of the economic uncertainty shocks for the dynamics of the variables of interest.

The simulation results from the structural VAR models reveal that an unexpected rise in global economic uncertainty, seen as a US EPU shock, has a negative impact on real sector activity in all the economies analysed, though the impact differs somewhat across the countries. Domestic uncertainty shocks also tend to exert a negative effect on local production, but the reaction is heterogeneous across countries. Deeper investigation highlights the important role played by the exchange rate in the process of adjustment. Most notably the real effective exchange rates in the United States and in the domestic economies react very differently to uncertainty shocks. A surge in both the US and domestic EPU indexes always triggers a depreciation of the domestic currency, while a rise in the US EPU leads the US dollar to appreciate. The outcome can be interpreted as resulting from the status of the US dollar as a safe haven. What is even more important is that we find the effects of both foreign

\footnotetext{
1 If we skip the first criterion, then we can extend the analysis to include Mexico and Chile as well, which are in an emerging market group. We discuss these two cases in the robustness analysis in Sect. 7.
} 
and domestic EPU shocks on local currencies to vary substantially across the economies analysed.

The rest of the paper is structured as follows. Section 2 presents the data and Sect. 3 the methodology. Section 4 discusses the effect of a US economic policy uncertainty shock on the US economy. Section 5 considers the effect of foreign and domestic economic policy uncertainty shocks on the four economies analysed. Section 6 presents the results of the forecast variance decompositions. Section 7 discusses some alternative specifications and robustness checks. Section 8 provides the final comments.

\section{Data}

We use structural VAR models to analyse the effects of domestic and foreign economic uncertainty shocks on economic developments in the four open economies of Canada (CAN), South Korea (KOR), Sweden (SWE), and the United Kingdom (UK). Each model consists of five variables for the country considered and the same five variables for the US. The variables are the consumer price index, the industrial production, the index of Economic Policy Uncertainty, the real effective exchange rate, and the three-month interbank interest rate.

The series are downloaded from the Federal Reserve Economic Data (FRED) database. The consumer price and industrial production indexes are seasonally adjusted, while the other variables do not exhibit seasonality. The real effective exchange rate is calculated as the weighted average of the bilateral exchange rates for the 60 largest trading partners of the country, and deflated using relative consumer prices; a rise in the real effective exchange rate indicates a real appreciation, while a decline shows a real depreciation. The three-month interest rate is annualised and given in decimal terms, so that for instance 0.05 indicates an annualised three-month interest rate of $5 \%$.

The EPU indexes are obtained from the website https://www.policyuncertainty. $\mathrm{com} /$, which is a webpage created and maintained by the authors of Baker et al. (2016). Given that only EPU indexes based on newspaper articles are available for the four small economies, the same news-based index is also used for the US to ensure consistency. The news-based EPU index measures the coverage in major US newspapers of policy-related economic uncertainty. ${ }^{2}$ It is a measure of the frequency of terms like 'uncertainty', 'economy', 'congress', 'legislation', 'white house', and 'regulation'. The news-based EPU indexes for the four small economies are constructed in a similar way but adapted to take account of the different languages and the terms indicating uncertainty.

\footnotetext{
${ }^{2}$ A broader measure of EPU that covers three components is available for the US. The first component is the news-based index discussed in the main text, the second captures temporary tax measures, and the third captures disagreement between professional economic forecasters. Since not all of the EPU indexes for the four open economies in our sample contain all the three components, we use only the first component, i.e. the news-based index.
} 


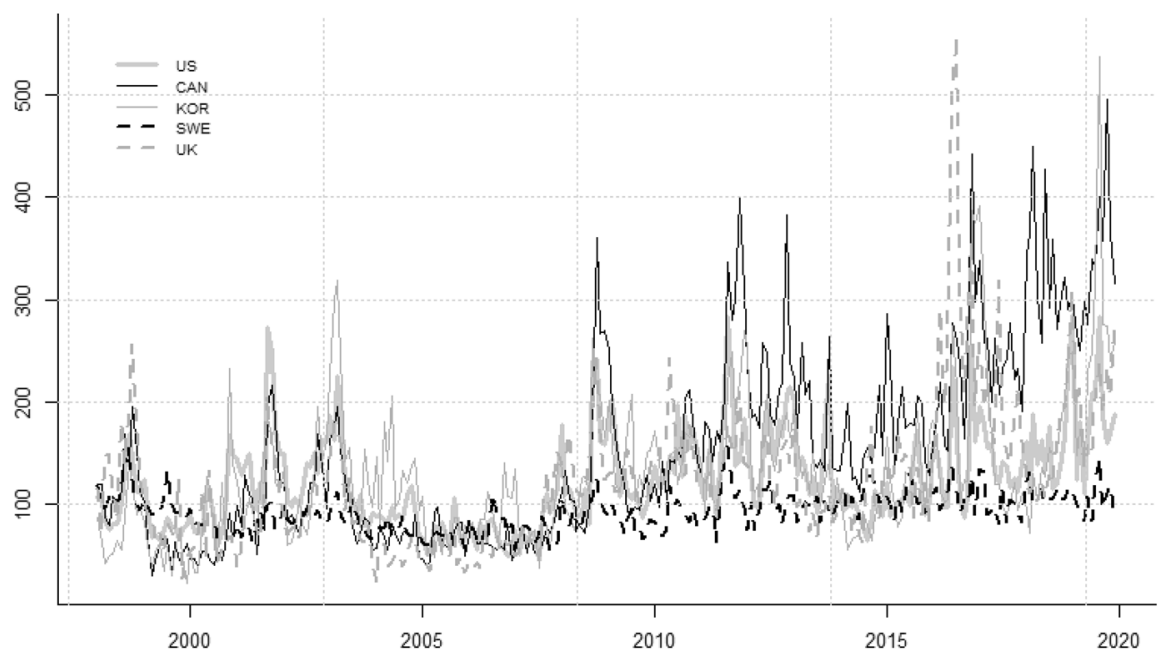

Fig. 1 Economic Policy Uncertainty index

All the data series are monthly and the sample runs from January 1998 to December 2019. The sample starts in January 1998 because the EPU index for the UK is available from this month, while the end of the sample is chosen so that the unusual developments that occurred during the coronavirus pandemic do not enter the sample.

Figures 1 and 2 present the values of all the series, and Table 1 describes their main statistical characteristics. The first two columns of Table 1 reveal that the series typically are nonstationary and integrated of order one with the exception of the EPU indexes which are stationary for the US and the four countries considered. The next columns indicate that the annualised dynamics of the endogenous variables are heterogeneous across countries. For instance, the average level of CPI inflation ranged between $1.22 \%$ in Sweden and $2.30 \%$ in South Korea. The annualised growth rate of industrial production meanwhile stood at an impressive $5.36 \%$ in South Korea and a disappointing $-0.25 \%$ in the UK. The range for the level of the interest rate is from $1.74 \%$ to $4.16 \%$. The Korean won experienced an appreciating trend of $1.79 \%$ per year over the period considered, while the Swedish krona depreciated at a rate of $1.43 \%$. Finally, the table also shows that the level of the EPU index was on average increasing by $5.01 \%$ per year in South Korea, while it was declining by $1.20 \%$ per year in Sweden. It can also be seen that EPU in the US was on a rising trend with the slope of $2.54 \%$ per year.

\section{Methodology}

We estimate for each of the four countries considered a VAR model and then identify the structural shocks using a recursive identification scheme. This scheme is flexible and allows the inclusion of many endogenous variables in the models. The 

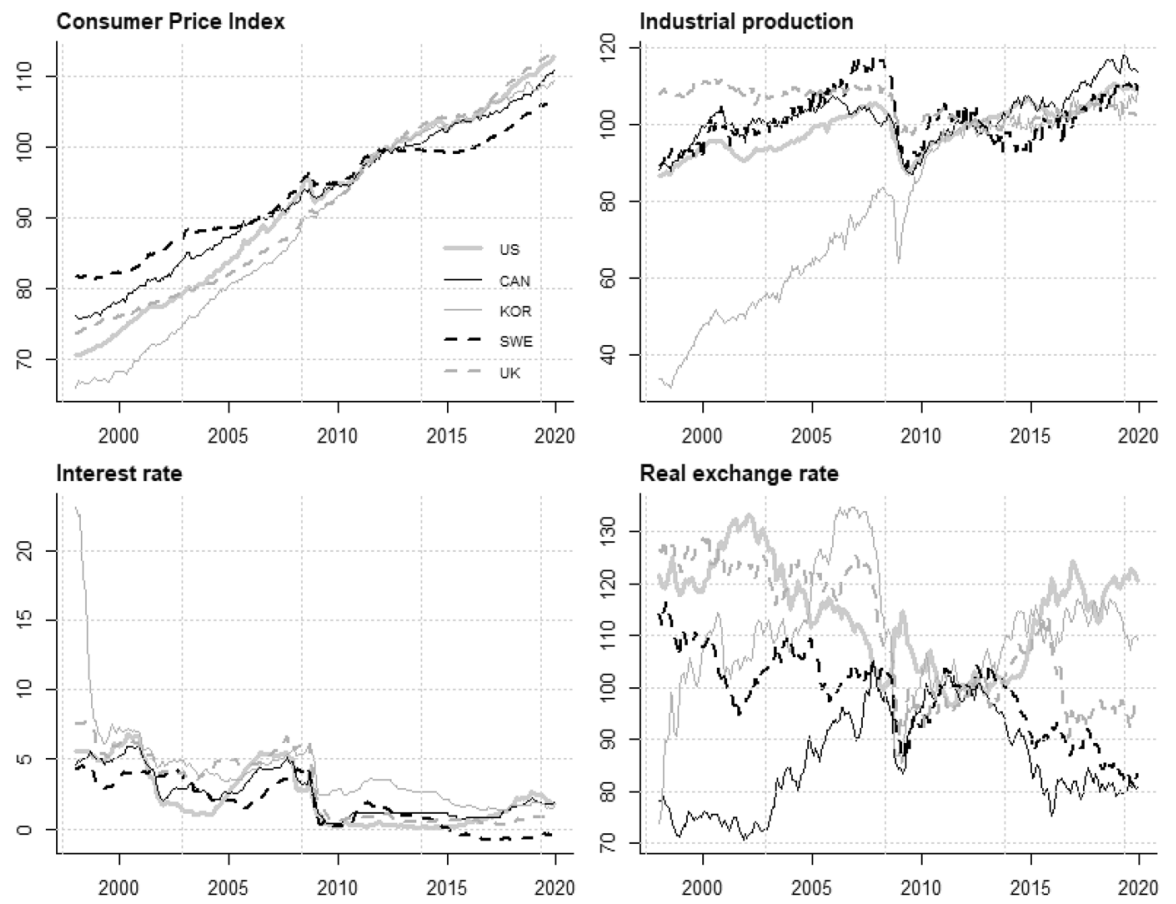

Fig. 2 Macroeconomic variables

vast majority of studies in the literature on policy uncertainty and spillovers also use VAR models and recursive identification. The most prominent example is the seminal study by Baker et al. (2016), which considers only one country, but a number of studies which consider spillovers between two countries also use the methodology, including Colombo (2013), Stockhammar and Österholm $(2016,2017)$ and Nilavongse et al. (2020). ${ }^{3}$

Each model for the four countries consists of global and local variables, with the global ones coming from the United States (superscript US). The VAR model describes the dynamics of ten variables: the log of the consumer price index $\left(P_{t}^{\mathrm{US}}, P_{t}^{i}\right)$, the $\log$ of industrial production $\left(I P_{t}^{\mathrm{US}}, I P_{t}^{i}\right)$, the $\log$ of the Economic Policy Uncertainty index $\left(E P U_{t}^{\mathrm{US}}, E P U_{t}^{i}\right)$, the log of the real effective exchange rate $\left(\right.$ REER $_{t}^{\mathrm{US}}$, REER $\left._{t}^{i}\right)$, and the three-month interbank interest rate $\left(\right.$ Rate $_{t}^{\mathrm{US}}$, Rate $\left._{t}^{i}\right)$. The superscript $i$ indicates one of the four open countries analysed. The data are described in Sect. 2.

The exact representation of the SVAR for country $i$ can be written as follows:

\footnotetext{
3 We have considered using VECM models, but these would require well-defined equilibrium relationships, which are not straightforward to devise in models with two countries and spillovers across the countries. No studies in the literature on the impact of policy uncertainty on the economy have used VECM models.
} 
Table 1 Descriptive statistics

\begin{tabular}{|c|c|c|c|c|c|c|c|c|}
\hline & \multicolumn{2}{|c|}{ ADF test } & \multicolumn{6}{|c|}{ Moments for variables in differences } \\
\hline & Level & Diffs & Mean & SD & Skew & Kurt & $\mathrm{ACF}(1)$ & $\operatorname{ACF}(2)$ \\
\hline & \multicolumn{8}{|c|}{ Consumer Price Index } \\
\hline US & -1.87 & -10.91 & 2.13 & 0.97 & -1.38 & 13.81 & 0.41 & -0.01 \\
\hline CAN & -2.18 & -13.32 & 1.71 & 1.05 & 0.25 & 4.10 & -0.06 & -0.11 \\
\hline KOR & 0.56 & -10.25 & 2.30 & 1.00 & 0.64 & 4.78 & 0.12 & 0.04 \\
\hline SWE & -1.53 & -9.43 & 1.22 & 0.80 & -1.20 & 10.17 & 0.12 & 0.14 \\
\hline \multirow[t]{2}{*}{ UK } & -1.29 & -8.76 & 1.94 & 0.55 & 0.32 & 4.55 & 0.14 & 0.19 \\
\hline & \multicolumn{8}{|c|}{ Industrial Production } \\
\hline US & -1.85 & -8.17 & 1.07 & 2.28 & -1.79 & 12.92 & 0.20 & 0.24 \\
\hline CAN & -1.84 & -10.48 & 1.15 & 3.53 & -0.21 & 4.04 & 0.09 & 0.05 \\
\hline KOR & -2.07 & -10.80 & 5.36 & 7.80 & -0.86 & 7.91 & -0.03 & 0.07 \\
\hline SWE & -2.19 & -13.63 & 0.90 & 7.23 & -0.03 & 3.77 & -0.30 & 0.05 \\
\hline \multirow[t]{2}{*}{ UK } & -2.07 & -13.01 & -0.25 & 3.08 & -0.65 & 5.90 & -0.21 & 0.01 \\
\hline & \multicolumn{8}{|c|}{ Economic Policy Uncertainty } \\
\hline US & -5.84 & -15.03 & 2.54 & 94.8 & 0.52 & 4.81 & -0.22 & -0.12 \\
\hline CAN & -4.91 & -13.49 & 4.42 & 98.4 & 0.20 & 3.45 & -0.24 & 0.00 \\
\hline KOR & -5.68 & -14.60 & 5.01 & 123.1 & 0.35 & 3.76 & -0.27 & -0.04 \\
\hline SWE & -6.48 & -16.79 & -1.20 & 59.0 & 0.28 & 3.37 & -0.29 & -0.15 \\
\hline \multirow[t]{2}{*}{ UK } & -4.61 & -15.85 & 3.95 & 111.6 & -0.16 & 4.73 & -0.30 & -0.09 \\
\hline & \multicolumn{8}{|c|}{ Interest Rate } \\
\hline US & -1.52 & -8.77 & 2.29 & 0.78 & -3.31 & 28.42 & 0.36 & 0.16 \\
\hline CAN & -2.14 & -6.62 & 2.50 & 0.54 & -1.39 & 7.64 & 0.58 & 0.40 \\
\hline KOR & -8.82 & -5.34 & 4.16 & 1.38 & -4.79 & 29.79 & 0.66 & 0.55 \\
\hline SWE & -2.92 & -6.19 & 1.74 & 0.55 & -3.38 & 26.37 & 0.54 & 0.45 \\
\hline \multirow[t]{2}{*}{ UK } & -2.19 & -8.02 & 2.97 & 0.65 & -4.24 & 34.07 & 0.53 & 0.26 \\
\hline & \multicolumn{8}{|c|}{ Real Exchange Rate } \\
\hline US & -1.48 & -10.51 & -0.04 & 4.13 & 0.26 & 4.36 & 0.35 & 0.00 \\
\hline $\mathrm{CAN}$ & -1.41 & -10.09 & 0.14 & 5.60 & -0.27 & 6.41 & 0.24 & 0.04 \\
\hline KOR & -3.71 & -11.87 & 1.79 & 7.47 & -0.54 & 10.39 & 0.38 & -0.05 \\
\hline SWE & -2.73 & -11.33 & -1.43 & 4.64 & 0.25 & 3.95 & 0.20 & -0.07 \\
\hline UK & -2.23 & -10.60 & -1.14 & 5.34 & -0.79 & 5.36 & 0.11 & 0.02 \\
\hline
\end{tabular}

The Augmented Dickey-Fuller (ADF) test specification includes a trend for variables in levels and a constant for variables in differences; in both cases one lag was included. The $1 \%, 5 \%$ and $10 \%$ critical values are $-3.98,-3.34$ and -3.13 for levels, and $-3.44 ;-2.87$ and -2.57 for differences. The mean value and standard deviation are rescaled so that they refer to annualised growth rates. The only exception is for the mean value of interest rates, which refers to the level of variable

$$
\mathbf{A} \mathbf{x}_{i t}=\boldsymbol{\Gamma}+\mathbf{A}(L) \mathbf{x}_{i t}+\mathbf{\epsilon}_{i t}, \mathbf{\epsilon}_{i t} \sim N(0, \mathbf{I})
$$

where $\mathbf{x}_{i t}=\left[P_{t}^{U S}, P_{t}^{i}, I P_{t}^{U S}, I P_{t}^{i}, E P U_{t}^{U S}, E P U_{t}^{i}, \text { Rate }_{t}^{U S}, \text { Rate }_{t}^{i}, R E E R_{t}^{U S}, R_{E E R_{t}^{i}}^{\prime}\right]^{\prime}$ is a vector of endogenous variables, $\boldsymbol{\Gamma}$ is a vector of constants, $\mathbf{A}$ is the identification matrix, and $\mathbf{A}(L)=\mathbf{A}_{1} L+\cdots+\mathbf{A}_{p} L^{p}$ denotes a lag polynomial of order $p$. Finally, $\mathbf{\epsilon}_{i t}$ is a vector of IID error terms. 
For each country, we proceed as follows. First, we set the maximum lag $p$ to two months. Table 3 in Appendix I shows the results of the Akaike information criterion (AIC), the Hannan-Quinn criterion (HQ) and the Schwarz criterion (SC) for each of the models for the four open economies. The criteria were typically minimised at a lag length of 2 although in some cases also lag length 1 or 3 . These results make us choose a lag length of 2 for all four VAR models. The choice of the same lag length has the added advantage that it makes the results as comparable as possible across the countries analysed.

Second, to account for potential over-parameterisation and problems stemming from the non-stationarity of the endogenous variables, we estimate the parameters of the VAR model using Bayesian inference methods. Specifically we assume the standard Minnesota prior, with the prior centred around the random walk with precision determined by the standard values of hyper-parameters: overall tightness $\lambda_{1}=0.1$, weight $\lambda_{2}=1$, lag decay $\lambda_{3}=1$ and tightness around the constant $\lambda_{4}=100$ (Dieppe et al. 2016, p. 28).

Third, to take account of the vector of endogenous variables $x_{i t}$ containing five global variables and five local ones, we apply a block exogeneity restriction so that the local variables do not Granger cause the global variables. We do this by imposing a very tight prior centred at zero for the relevant parts of matrices $\mathbf{A}_{i}$ for $i=1,2, \ldots, p$ (Dieppe et al. 2016, p. 28). This block exogeneity restriction combined with the same choice for the maximum lag length ensures that the dynamics of the global variables are the same in the VAR models for all the economies analysed. It may be noted that in economic terms the block exogeneity means that we assume that the four countries analysed can be classified as "small open economies", so domestic shocks do not affect the global variables. This small open economy assumption is common in the literature for the four economies analysed (Adolfson et al. 2008; Justiniano and Preston 2010; Stockhammar and Österholm 2017; Kolasa and Rubaszek 2018).

In the last stage, we draw parameters from the posterior distribution, and for each draw we calculate the impulse response function to the structural shocks $\mathbf{\epsilon}_{i t}$ by employing the standard Cholesky identification scheme. The identification of the structural shocks depends on the ordering of the endogenous variables in the vector $\mathbf{x}_{i t}$. Our choice follows the common rule that slow-moving variables should be ordered before faster-moving ones; see e.g. Christiano et al. (1999, 2005). This means that the financial variables (the interest and exchange rates) are ordered after the EPU variable, as pricing in these markets might immediately incorporate any new information related to EPU shocks. Industrial production and prices are expected to adjust with a lag; in our specification, the price index and industrial production can only react to the EPU variables, the interest rates and the real exchange rates with a lag. These considerations imply that the variables of the model are ordered in the following sequence: $\left[P_{t}^{\mathrm{US}}, P_{t}^{i}, I P_{t}^{\mathrm{US}}, I P_{t}^{i}, E P U_{t}^{\mathrm{US}}, E P U_{t}^{i}\right.$, Rate $_{t}^{\mathrm{US}}$, Rate $\left._{t}^{i}, \operatorname{REER}_{t}^{\mathrm{US}}, \operatorname{REER}_{t}^{i}\right]$.

The estimation of the VAR models and the simulation of the impulse responses from the identified models were carried out in $\mathrm{R}$ package. Each of the ten equations of the VAR model has 10 regressors with two lags plus a constant, so that the total number of estimated parameters amount to 210 for each of the four countries. Detailed estimation results are available from the corresponding author upon 


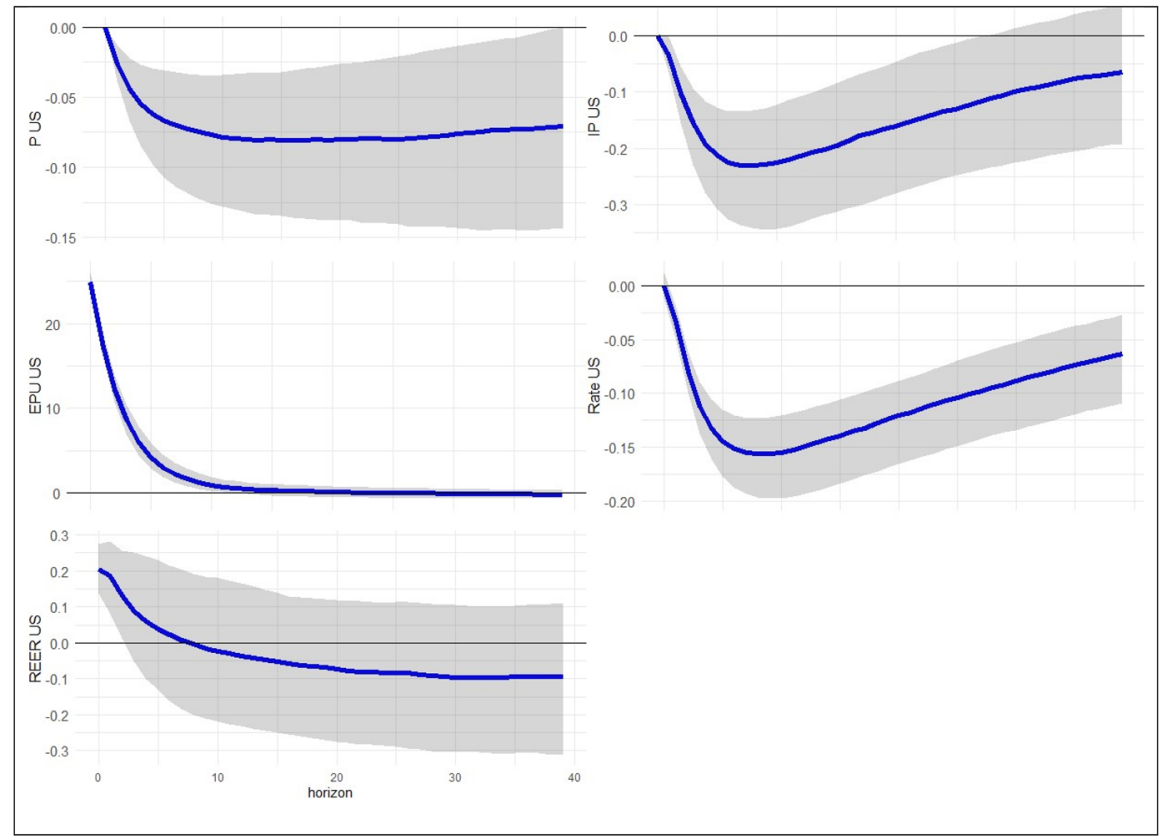

Note: The shaded area indicates the $68 \%$ credible interval.

Fig. 3 The effects of US EPU shocks in the US. Note: The shaded area indicates the $68 \%$ credible interval

request. These include the posterior means, the standard deviations, Monte Carlo Standard Errors (MCSEs) and the eigenvalues used to assess the stability of the estimated models. All of the eigenvalues are below 1 for each of the four countries, which means that the impulse-response functions and the forecast-error variance decompositions will eventually converge to their steady states and so can interpreted in standard ways.

\section{Effects of a US EPU shock on the US economy}

In this section we describe the response of the US economy to a US EPU shock, which is necessary for understanding the results in the next section, in which we discuss how these shocks affect the other four economies. Given the assumption of a small, open economy, which implies that there is no feedback from countries analysed to the US, the impulse response functions from the US EPU shock to the US macroeconomic variables are identical across the VAR models.

Figure 3 presents the impulse response functions (IRFs) of the US variables to an unexpected one standard deviation shift in economic uncertainty. It can be seen that the instantaneous reaction of the interest rate is small, while the real exchange rate appreciates markedly. In the subsequent periods, the shock leads to declines in both the price level and industrial production because of a decline in aggregate domestic 
demand and an appreciation of the real exchange rate. These results are largely in line with those obtained in Colombo (2013), Baker et al. (2016), Stockhammar and Österholm (2017), and Nilavongse et al. (2020), who find that an increase in the US EPU has a negative effect on the US real sector.

Figure 3 shows for the values that are important for our subsequent investigation that the maximum decline after the EPU shock of $0.25 \%$ in industrial production and of 0.15 percentage point in interest rates is reached about six months after the shock occurs. Prices fall, and then stabilise at about $0.1 \%$ below their initial level. Finally, the real exchange rate sees an initial appreciation of around $0.2 \%$ that is gradually eliminated within the subsequent six months. This finding may be interpreted as reflecting a flight to safety where investors perceive the US dollar to be a safe haven currency even when EPU increases in the US.

\section{The effects of uncertainty shocks on the four open economies}

This section presents the main results of our investigation into the effects of global and domestic EPU shocks on economic developments in Canada, South Korea, Sweden and the UK. We organise our discussion by focusing on each country separately in turn.

\subsection{Canada}

The left column of Fig. 4 shows that an increase in Canadian EPU leads to a rise in industrial production and possibly also in the price level although the latter effect is very imprecisely determined. The higher production is qualitatively different from the response of the US economy discussed in Sect. 4, and it may due to the shortlived decline in the interest rate and the substantial and sustained depreciation in the real effective exchange rate. The depreciation may reflect investors reacting to the elevated domestic economic uncertainty by leaving the Canadian dollar due to safety concerns. This finding highlights the importance of the exchange rate channel in the adjustment after a local EPU shock.

The right column of Fig. 4 reveals that an unexpected rise in US EPU has noticeable effects on the Canadian economy. The shock, together with the resulting macroeconomic developments in the US economy discussed in Sect. 4, results in an increase in EPU, a substantial but short-lived decline in industrial production, and lower interest rates in Canada. The peak decline in industrial production of about $0.15 \%$ is observed around six months after the shock. There is a modest depreciation in the real effective exchange rate but it is significant only in the initial periods when the credible interval of the impulse response does not include zero. The short-lived depreciation may be due to investors seeking protection in the US dollar in reaction to the rising uncertainty and the slumps in both the US and Canadian economies. It is noticeable however that the depreciation of the Canadian dollar is much stronger after a domestic uncertainty shock than it is after a global one, as shown in Fig. 4. 


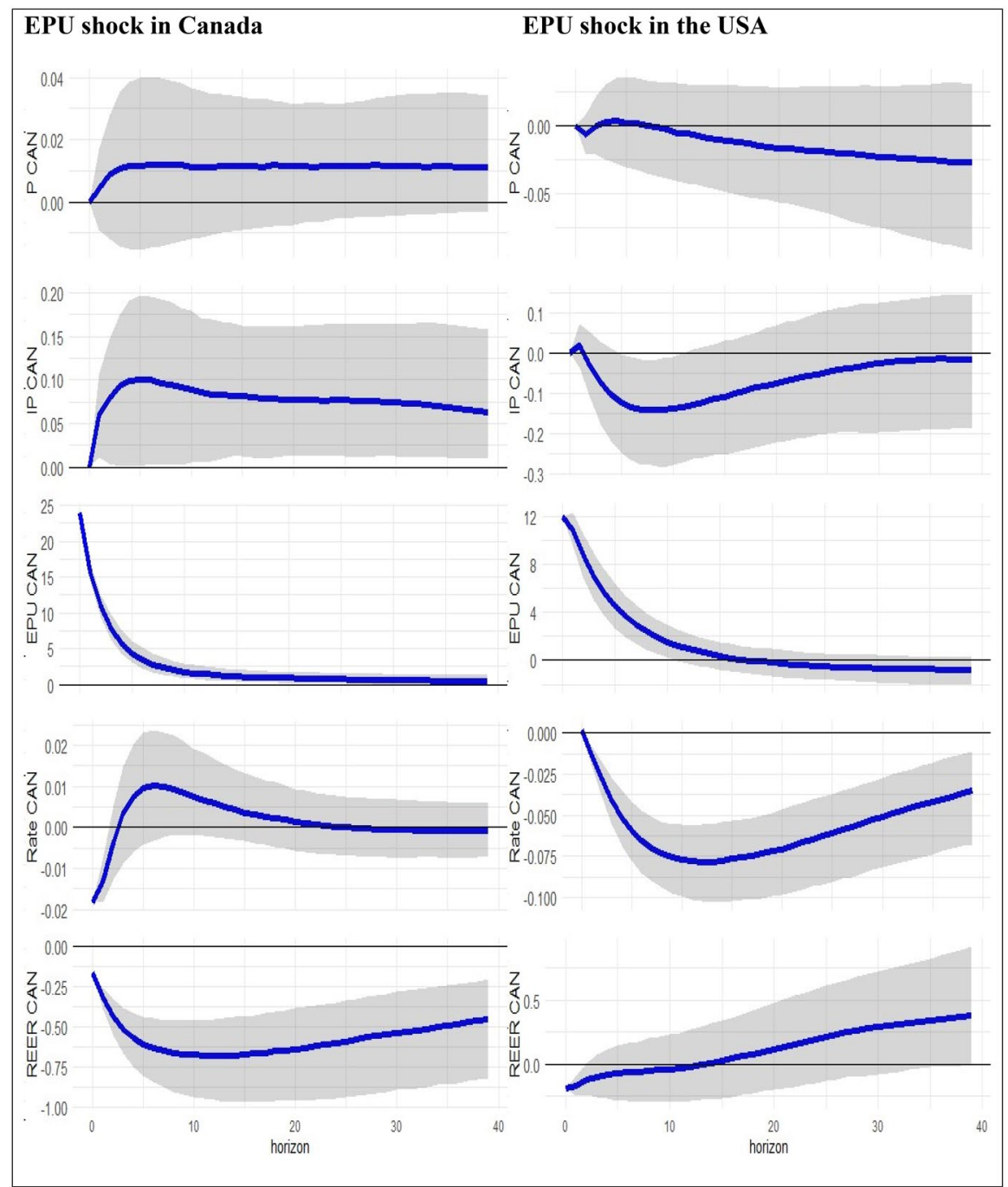

Note: The shaded area indicates the $68 \%$ credible interval.

Fig. 4 The effects of EPU shocks in Canada. Note: The shaded area indicates the $68 \%$ credible interval

\subsection{South Korea}

The left panel of Fig. 5 shows that a rise in the Korean EPU index has a negative effect on industrial production and at various times also on the price level and the interbank rate. The decline in industrial production, which amounts to $0.2 \%$ at its extreme, is of significance throughout the entire horizon of the analysis as the credible interval is below zero for virtually all of the 40 months. Even though the Korean real effective exchange rate depreciates, the scale of the depreciation is not sufficient to avert a decline in industrial production and the price level. The effects of the 


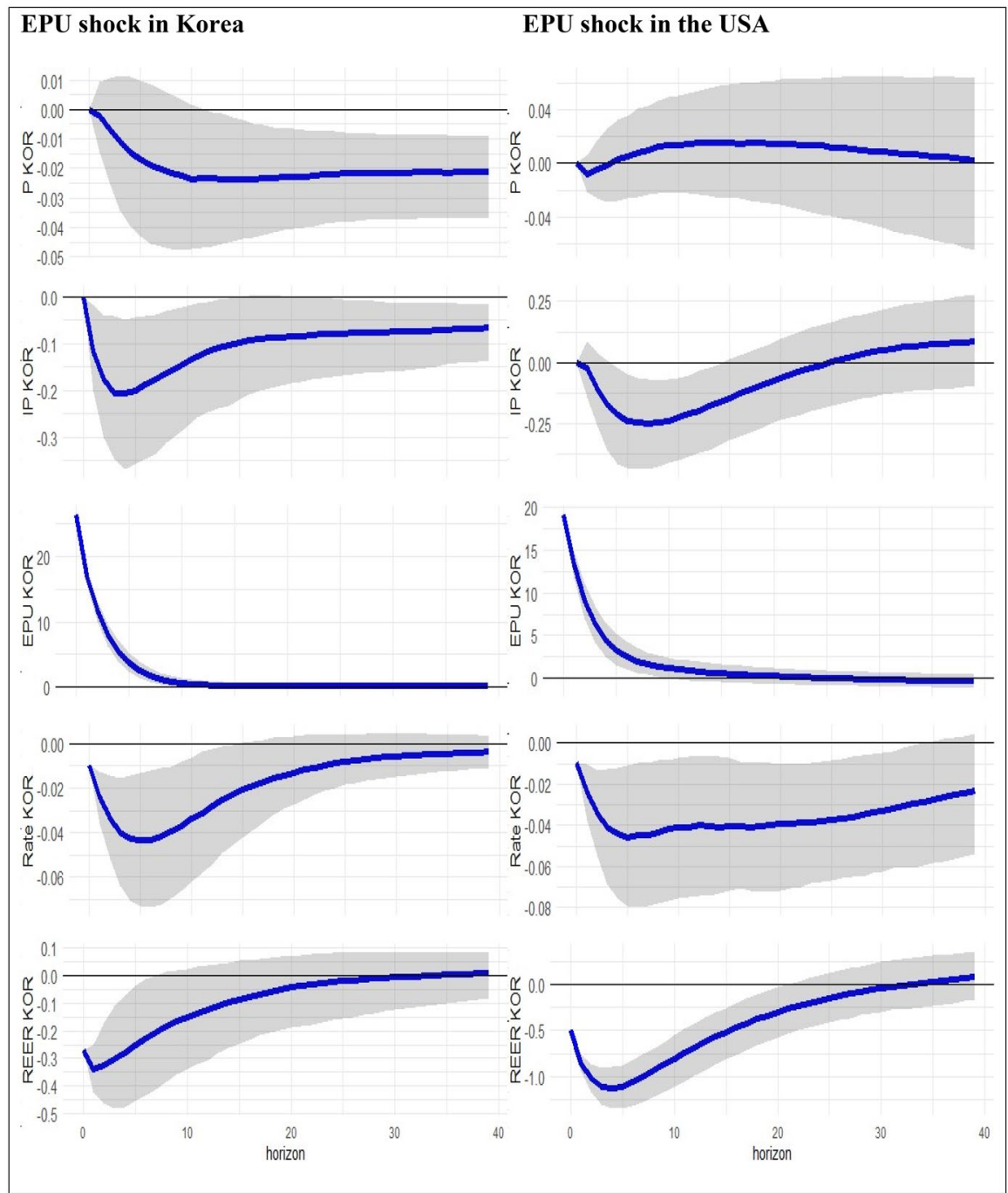

Note: The shaded area indicates the $68 \%$ credible interval.

Fig. 5 The effects of EPU shocks in South Korea. Note: The shaded area indicates the $68 \%$ credible interval

domestic EPU shock in Korea differ markedly from those in Canada, most probably because the reaction of the real effective exchange rate is of different size in the two countries.

The right panel of Fig. 5 illustrates that the global EPU shock in the US affects the Korean economy in several ways. One noticeable effect is a very large increase in domestic EPU. The change in the Korean EPU is almost one standard deviation, and this large increase may contribute to the considerable but relatively short-lived fall 
in industrial production. It is noticeable that industrial production declines despite the relatively substantial depreciation of the real effective exchange rate. The price level does not change a great deal, perhaps because the effects of declining industrial production and the depreciation of the real effective exchange rate counteract each other. The subsequent fall in the three-month interest rate is fairly persistent, possibly reflecting the subdued sentiment, declining industrial production, and limited price pressure.

\subsection{Sweden}

Figure 6 displays the response of the Swedish economy to the local and global EPU disturbances. The local event triggers a fall in industrial production that reaches a largest extent of around $0.25 \%$ after three months and is significantly negative throughout the entire first year, as the credible interval is below zero for this period. It may be noted that the scale of the decline is broadly similar to that in the case of Korea. The real effective exchange rate depreciates, but the effect is limited to the first three months. The maximum response of the Swedish real effective exchange rate is in general smaller than the responses of the Canadian and Korean currencies.

The EPU shock in the US has a negative but insignificant impact on industrial production and the price level. The negative impact on the two variables is mitigated by a significant fall in the interest rate. The global shock also leads to a short-lived depreciation in the Swedish real effective exchange rate, followed by an appreciation beginning in the second year. Overall, both foreign and domestic EPU shocks are found to have relatively limited effects on the Swedish real effective exchange rate.

\subsection{United Kingdom}

Figure 7 shows the effects of EPU shocks on the UK variables. The effect of an unexpected spike in domestic EPU on industrial production is modest and insignificant as the $68 \%$ credible interval includes zero at all horizons. The reason for this might be that depressed domestic demand is counterbalanced by the stimuli from a lower interest rate and the depreciation of the real effective exchange rate. The side effect of the real depreciation is seen in the upward pressure on the price level.

Figure 7 also demonstrates that a US EPU shock leads to a decline in production although the effect is imprecisely estimated as that the $68 \%$ credible interval includes zero at all horizons. The EPU shock is leads to a sizeable depreciation in the real effective exchange rate but only for approximately one year. The depreciation is in line with those in the other countries analysed, where the domestic currencies similarly depreciate after a surge in foreign EPU. The interest rate declines markedly over the first two years after the shock, which seems consistent with the dynamics of the real effective exchange rate. 


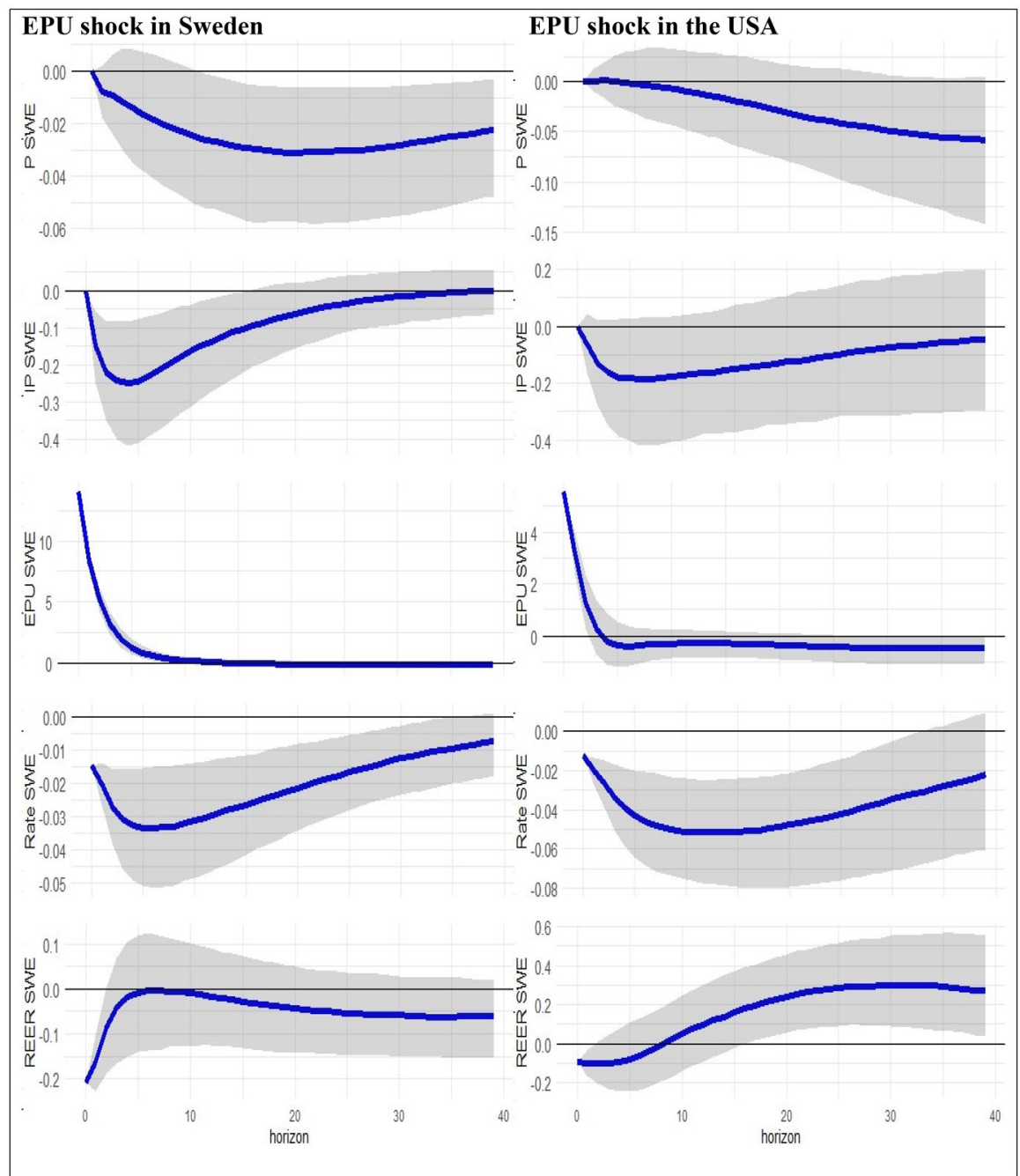

Note: The shaded area indicates the $68 \%$ credible interval.

Fig. 6 The effects of EPU shocks in Sweden. Note: The shaded area indicates the $68 \%$ credible interval

\section{Summary and comparison}

The analysis of the effects of US and domestic shocks to economic policy uncertainty provides a number of interesting results. Shocks to economic policy uncertainty, both local and global, have a meaningful impact on key macroeconomic variables in each of the four economies analysed. The analysis also reveals that some responses are relatively similar across the countries, while other responses exhibit substantial heterogeneity.

Focusing first on the effects of domestic economic policy uncertainty shocks shows that an increase in country-specific EPU leads to a depreciation in the 


\section{EPU shock in the UK}
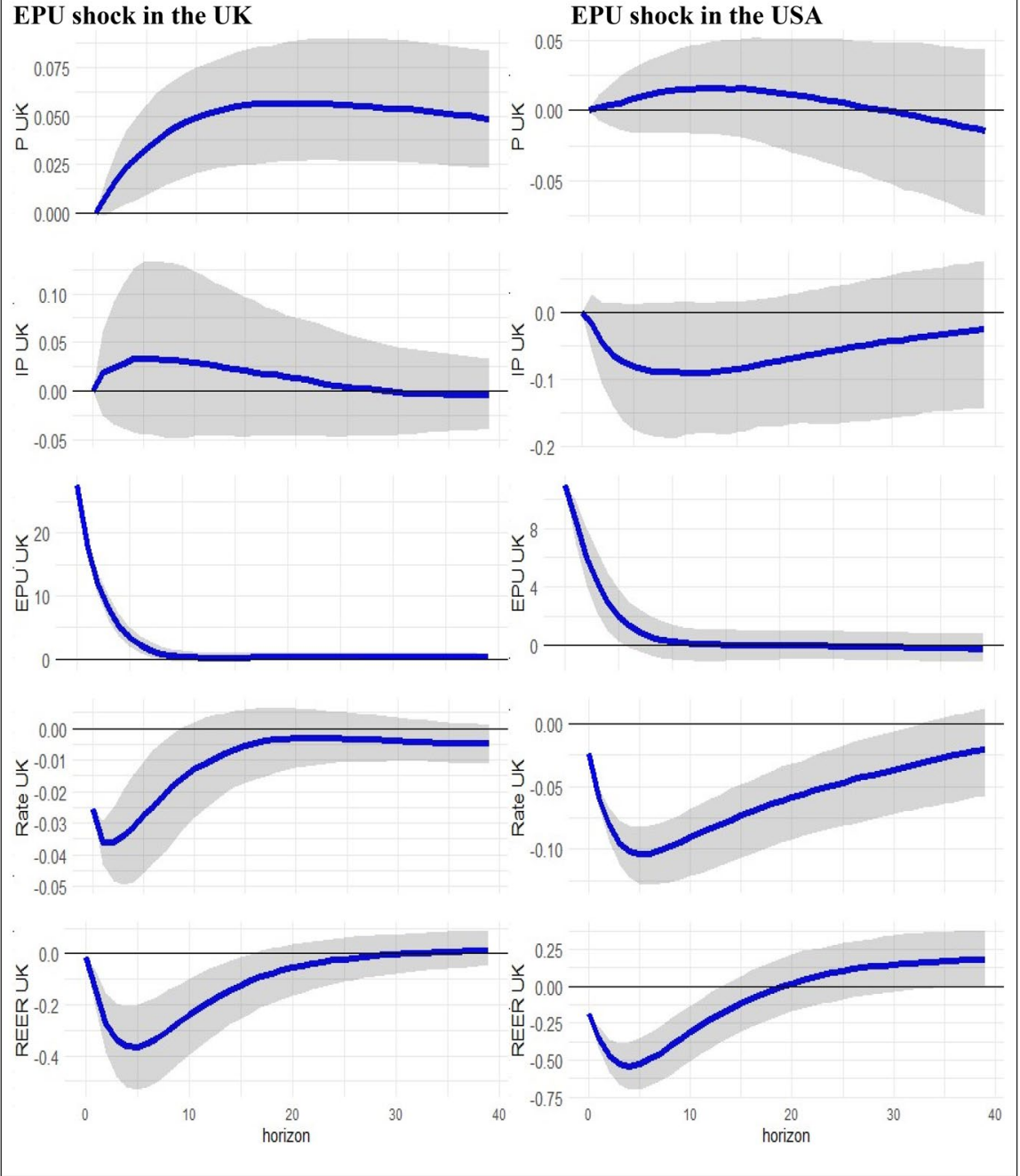

Note: The shaded area indicates the $68 \%$ credible interval.

Fig. 7 The effects EPU shocks in the UK. Note: The shaded area indicates the $68 \%$ credible interval

exchange rate in all the economies analysed. Moreover, the weakening of the currency is persistent in all the countries except Sweden. We further find that the response of industrial production is heterogeneous, as industrial production drops in South Korea and Sweden, but increases in Canada and the UK. The main reason for this outcome is that there is some degree of heterogeneity in the stabilising effect of the exchange rates and interest rates across the four countries. Finally, the price level responds differently to changes in the domestic EPU shock, in part reflecting the differing dynamics of the real economy and the real exchange rates in the four open economies analysed. 
There are also several findings related to how a foreign economic policy uncertainty shock affects the economies analysed. In all cases, a surge in the US EPU index has a negative effect on the real sector and leads to a depreciation in the real exchange rate. This result would be a reflection of the US dollar functioning as a safe haven in periods of elevated uncertainty. Next, there is some heterogeneity across countries in the magnitude and persistence of the reaction of the real exchange rate, as the US EPU shock has a stronger impact on the Korean won and the British pound than it does on the Canadian dollar and the Swedish krona. These results are in line with Kido (2016), who finds that when US EPU increases, the exchange rates of several currencies tend to depreciate.

In summary, rises in both US EPU and domestic EPU lead the exchange rate to depreciate in each of the four economies, while a rise in US EPU leads the US dollar to appreciate. These results can be interpreted as illustrating a flight to safety, where investors perceive the US dollar as a safe haven irrespective of whether the increased economic uncertainty emanates from the US or from the open economies analysed.

\section{Forecast error variance decomposition}

The analysis in Sect. 5 showed that the macroeconomic variables in each of the four economies analysed react to both foreign and domestic EPU shocks, though to varying degrees across the four economies. A key driver of the results appears to be the reaction of the exchange rate to EPU shocks, as the negative effects of increased uncertainty in either the US or the domestic economy are in many cases counteracted by a depreciation of the real exchange rate.

In this section we present the results of forecast error variance decompositions, which make it possible to gauge, for instance, the contribution of domestic and foreign EPU shocks to the volatility of industrial production and the real effective exchange rate. The results in Table 2 indicate that domestic uncertainty shocks explain only a small fraction of the variation in industrial production in the four countries. Local shocks to economic uncertainty or sentiment are generally of limited importance for real economic developments. The table also shows that EPU shocks emanating from the US similarly explain a small fraction of the variation in industrial production, although slightly more than domestic shocks do. These results of the forecast error variance decomposition of industrial production in the four economies are fully in line with those for the euro area reported in Colombo (2013).

Although EPU shocks do not appear to be very important for the real economy, they turn out to be a meaningful source of fluctuations in the real effective exchange rate. Domestic EPU shocks are particularly important for Canada and the UK; this is consistent with the impulse responses reported in Sect. 5, where the real effective exchange rate in both these countries depreciates substantially after the shock. Meanwhile, the global EPU shock explains a large part of the variation in the real effective exchange rates for South Korea and the UK, and explains it to a lesser extent for Sweden. These findings illustrate how the exchange rate, as a fast-moving financial variable, is highly susceptible to economic sentiment shocks such as those captured by the EPU variable. 
Table 2 Forecast error variance decomposition

\begin{tabular}{|c|c|c|c|c|}
\hline \multirow[t]{2}{*}{$\begin{array}{l}\text { Horizon } \\
\text { (in months) }\end{array}$} & \multicolumn{2}{|c|}{ Industrial production } & \multicolumn{2}{|c|}{$\begin{array}{l}\text { Real effective } \\
\text { exchange rate }\end{array}$} \\
\hline & $E P U^{i}$ & $E P U^{\mathrm{US}}$ & $E P U^{i}$ & $E P U^{\mathrm{US}}$ \\
\hline & \multicolumn{4}{|c|}{ Canada } \\
\hline 1 & 0.0 & 0.0 & 2.2 & 0.9 \\
\hline 3 & 0.4 & 0.0 & 6.2 & 0.6 \\
\hline 6 & 0.7 & 0.7 & 11.6 & 0.3 \\
\hline 12 & 1.0 & 1.7 & 17.7 & 0.2 \\
\hline 24 & 1.2 & 1.6 & 21.1 & 0.3 \\
\hline \multirow[t]{2}{*}{36} & 1.5 & 1.2 & 20.7 & 1.2 \\
\hline & \multicolumn{4}{|c|}{ South Korea } \\
\hline 1 & 0.0 & 0.0 & 1.7 & 8.3 \\
\hline 3 & 0.4 & 0.1 & 2.0 & 18.4 \\
\hline 6 & 1.1 & 1.0 & 1.9 & 26.8 \\
\hline 12 & 1.5 & 2.4 & 1.6 & 29.2 \\
\hline 24 & 1.4 & 2.4 & 1.2 & 24.0 \\
\hline \multirow[t]{2}{*}{36} & 1.4 & 2.1 & 1.1 & 21.0 \\
\hline & \multicolumn{4}{|c|}{ Sweden } \\
\hline 1 & 0.0 & 0.0 & 1.8 & 0.8 \\
\hline 3 & 0.9 & 0.2 & 1.1 & 1.0 \\
\hline 6 & 2.0 & 0.8 & 0.6 & 1.1 \\
\hline 12 & 2.6 & 1.4 & 0.4 & 0.8 \\
\hline 24 & 2.2 & 1.7 & 0.4 & 2.7 \\
\hline \multirow[t]{2}{*}{36} & 1.9 & 1.6 & 0.5 & 6.0 \\
\hline & \multicolumn{4}{|c|}{ United Kingdom } \\
\hline 1 & 0.0 & 0.0 & 0.5 & 2.0 \\
\hline 3 & 0.0 & 0.1 & 2.8 & 6.2 \\
\hline 6 & 0.1 & 0.6 & 6.1 & 10.7 \\
\hline 12 & 0.1 & 1.3 & 7.4 & 11.2 \\
\hline 24 & 0.1 & 1.8 & 5.6 & 7.8 \\
\hline 36 & 0.1 & 1.8 & 4.8 & 7.4 \\
\hline
\end{tabular}

\section{Robustness and extensions}

We produce several robustness checks and extensions to the baseline model. The results of these additional analyses are discussed in this section; the detailed results are available in the Online Appendix. Overall, we find that the results from the various alternative model specifications are consistent with those of our main model discussed in Sect. 5, including the finding that the US dollar appears to function as a safe haven when there is rising economic uncertainty.

First, we extend the sample period so that it starts from January 1994 instead of January 1998. We do this by merging the UK EPU index, which starts from January 1998, with the historical UK EPU index, which covers the period from January 1900 
to December 2008. More precisely, we use the historical UK EPU index from January 1994 to December 1997 and the current UK EPU index from 1998 onwards. The EPU indexes for the other countries are available from 1994. Figure A1 to A5 in the online appendix show the effects of EPU shocks in the model with extended sample size. We find that the main results remain unchanged, as the real effective exchange rates of all the economies depreciate after US and domestic EPU shocks. Moreover, there remains some heterogeneity across the countries in the magnitude and persistence of the currency dynamics. We find that an increase in US EPU has a negative impact on industrial production in the US and in the four open economies, while the impact of country-specific EPU shocks on industrial production differs across the countries. Overall, the results are qualitatively similar to those obtained with the data from 1998.

Second, we use the unemployment rate, obtained from FRED, instead of industrial production in the VAR model specifications. Figure B1 to B5 of the online appendix display the effects of EPU shocks in the model specification with unemployment. We find that the responses of unemployment to the US and domestic EPU shocks are heterogeneous across the four countries, in much the same way that the response of industrial production differs across countries. Furthermore, the domestic currencies depreciate after a rise in either domestic or foreign EPU. These results are in line with the baseline results from Sect. 5.

Third, we use the bilateral exchange rates against the US dollar instead of the real effective exchange rates. The results based on the model specification with bilateral exchange rates are presented in Fig. $\mathrm{C} 1$ to $\mathrm{C} 4$ in the online appendix. This substitution does not change the baseline results. A domestic EPU shock triggers a persistent depreciation in the currencies of all the economies. There is some heterogeneity across the countries in the magnitude and persistence of the currency dynamics, as the South Korean won and the British pound depreciate more than the currencies of Canada and Sweden do after an increase in US EPU.

Fourth, we consider the effect of incorporating capital markets into the VAR specifications in the form of the stock price indexes of the US and the open economies. We use the same variables as in the main model, but we now add the stock market indexes for the US and for the open economy being observed. Figure D1 to D5 in the online appendix show the effects of EPU shocks in the model specification with capital markets. A rise in domestic or US EPU has a negative impact on the stock market indexes in all four of the economies, as would be expected. Including the stock markets does not, however, change our finding that there is heterogeneity across the countries in the magnitude and persistence of the currency dynamics after uncertainty shocks. The US EPU shock has a stronger impact on the Korean won and the British pound than it has on the Canadian dollar and the Swedish krona. These results are consistent with the results from Sect. 5. Overall, the results are broadly unchanged, including the finding that the US dollar functions as a safe haven in periods of heightened uncertainty.

Fifth, we extend the sample of countries to two emerging economies with floating exchange rates by bringing in Mexico and Chile. According to Figure E1 and E2 in the online appendix, an increase in country-specific EPU leads to a depreciation in the exchange rate, while the responses of industrial production differ across the two countries. In all cases, a surge in US EPU has a negative effect on 
industrial production, while the real effective exchange rates of Mexico and Chile depreciate. These results conform to the results that we obtained for the set of four advanced countries.

Finally, we consider an alternative ordering of the endogenous variables in vector $\mathbf{x}_{i t}$ by assuming that the foreign block is ordered before the local block. This is an assumption used in a number of previous studies of spillovers from shocks in economic policy uncertainty (Colombo 2013; Stockhammar and Österholm 2016, 2017; Nilavongse et al. 2020). The alternative ordering implies the following ordering of the endogenous variables: $\quad\left[P_{t}^{\mathrm{US}}, I P_{t}^{\mathrm{US}}, E P U_{t}^{\mathrm{US}}\right.$, Rate $_{t}^{\mathrm{US}}, \operatorname{REER}_{t}^{\mathrm{US}}, P_{t}^{\mathrm{i}}, I P_{t}^{\mathrm{i}}, E P U_{t}^{\mathrm{i}}$, Rate $\left._{t}^{\mathrm{i}}, R_{E E R_{t}^{\mathrm{i}}}\right]$. The results based on the model specification with the alternative ordering are shown by Fig. F1 to F5. The results are overall in line with the baseline results from Sect. 5. We find for instance that the domestic currencies depreciate after a rise in either domestic or foreign EPU. However, the identification resulting from the baseline ordering may be more reasonable than the alternative ordering. For example, in the alternative model specification a rise in the US EPU triggers an immediate increase in industrial production in Canada and South Korea, which may not be reasonable. In our baseline model specification, there is no such immediate change in industrial production in Canada and South Korea.

\section{Final comments}

This paper analyses the macroeconomic effects in four open economies of economic policy uncertainty shocks emanating from the US and from the countries themselves. The economies are those of Canada, Korea, Sweden and the United Kingdom, all of which are countries with floating exchange rates and independent economic policymaking. The analysis is carried out using structural VAR models, in which shocks are identified using Cholesky decomposition. The economic policy uncertainty shocks identified may reflect extraneous economic policy initiatives, policy debates, concerns about future developments, or other sources of economic uncertainty.

The analysis shows that increased economic uncertainty in the US reduces industrial production in the small, open economies, and that the magnitudes of decline are relatively similar across the four countries. The effect of domestic uncertainty shocks varies substantially across the countries, as industrial output declines in Korea and Sweden, increases in Canada, and is largely unaffected in the United Kingdom.

The difference between the effects on industrial production of EPU shocks that emanate domestically or in the US can partly be attributed to the dynamics of the real effective exchange rate. Increased economic uncertainty in the US causes a real appreciation of the US dollar, which may aggravate the real effects on the US economy. In the small, open economies however, increased economic uncertainty, whether domestic or foreign, typically leads to a real depreciation, which moderates the real effects of the EPU shocks. Whereas the real effective exchange rate amplifies the effect of uncertainty shocks in the US, it typically functions as a shock absorber in the four small, open economies, particularly in the short term. This 
finding arguably reflects the role of the US as a safe haven in turbulent times, which the other four economies are not.

This discussion underscores the importance of how the real effective exchange rate reacts to uncertainty shocks and consequently the key role that it plays in the overall outcome of economic uncertainty shocks. This key finding essentially reflects how exchange rates can react instantaneously to new information and so are susceptible to shifts in expectations that may stem for instance from changes in economic policy uncertainty (Dornbusch 1976; Chang and Taylor 2003). The analysis also reveals substantial heterogeneity in how the real effective exchange rate adjusts in the US and in each of the four open economies analysed. The heterogeneity may reflect factors such as policymaking and institutional and structural features, which have not been included in the analysis at this stage. Our study provides a useful reference for further investigations of the relationship between different sources of uncertainty shocks and real exchange rates across countries.

The analysis in this paper has a number of distinct policy implications. First, policymakers should be aware that shocks to economic policy uncertainty have the potential to affect the economy in numerous ways. This suggests that monitoring and surveillance initiatives should also include sentiment indicators and measures of economic uncertainty. Importantly, it is generally as important to monitor sentiment indicators in the US as to observe those in the domestic economy, given the spillovers detailed in this study. Second, policymakers concerned about stability in the domestic business cycle may seek to avoid policies that induce policy uncertainty. This could be an argument for predictable and steady policies that reduce uncertainty in the general population. The third implication relates to the importance of the exchange rate as an absorber of shocks for the four open economies analysed, including shocks to economic policy uncertainty. This feature is a key argument for maintaining floating exchange rates in open economies that are buffeted by various shocks, including shocks to economic policy uncertainty. Finally, the results exhibit some heterogeneity across the countries analysed and this suggests that institutions and policies should take the particularities of the individual countries into account.

\section{Appendix I: Information criteria}


Table 3 Information criteria for VAR models

\begin{tabular}{|c|c|c|c|c|c|c|}
\hline Lag length $n$ & 1 & 2 & 3 & 4 & 5 & 6 \\
\hline & \multicolumn{6}{|c|}{ Canada } \\
\hline $\operatorname{AIC}(n)$ & -92.83 & -93.84 & -93.74 & -93.60 & -93.24 & -93.14 \\
\hline $\mathrm{HQ}(n)$ & -92.23 & -92.68 & -92.03 & -91.33 & -90.41 & -89.76 \\
\hline \multirow[t]{2}{*}{$\mathrm{SC}(n)$} & -91.31 & -90.95 & -89.48 & -87.95 & -86.22 & -84.74 \\
\hline & \multicolumn{6}{|c|}{ South Korea } \\
\hline $\operatorname{AIC}(n)$ & -89.05 & -89.78 & $\underline{-89.85}$ & -89.73 & -89.62 & -89.48 \\
\hline $\mathrm{HQ}(n)$ & -88.44 & $\underline{-88.62}$ & -88.13 & -87.46 & -86.79 & -86.10 \\
\hline \multirow[t]{2}{*}{$\mathrm{SC}(n)$} & $\underline{-87.54}$ & -86.89 & -85.58 & -84.08 & -82.59 & -81.08 \\
\hline & \multicolumn{6}{|c|}{ Sweden } \\
\hline $\operatorname{AIC}(n)$ & -92.54 & -93.47 & -93.48 & -93.35 & -93.12 & -92.95 \\
\hline $\mathrm{HQ}(n)$ & -91.93 & -92.31 & -91.76 & -91.08 & -90.29 & -89.57 \\
\hline \multirow[t]{2}{*}{$\mathrm{SC}(n)$} & -91.02 & -90.58 & -89.21 & -87.70 & -86.09 & -84.55 \\
\hline & \multicolumn{6}{|l|}{ UK } \\
\hline $\operatorname{AIC}(n)$ & -92.91 & -94.10 & -94.21 & -94.00 & -93.77 & -93.63 \\
\hline $\mathrm{HQ}(n)$ & -92.31 & -92.94 & -92.50 & -91.72 & -90.95 & -90.25 \\
\hline $\operatorname{SC}(n)$ & -91.40 & -91.21 & -89.95 & -88.35 & -86.75 & -85.23 \\
\hline
\end{tabular}

AIC denotes the Akaike information criterion, HQ the HannanQuinn criterion and SC the Schwarz criterion. The lag length at which the information criterion is minimised is underscored

Supplementary Information The online version contains supplementary material available at https://doi. org/10.1007/s11079-021-09656-0.

Acknowledgements We gratefully acknowledge valuable comments from the Guest Editors and two anonymous referees. The views expressed are those of the authors and not necessarily those of the Bank of Estonia or the Eurosystem.

\section{References}

Adolfson M, Laséen S, Lindé J, Villani M (2008) Evaluating an estimated New Keynesian small open economy model. J Econ Dyn Control 32:2690-2721

Baker SR, Bloom N, Davis SJ (2016) Measuring economic policy uncertainty. Quart J Econ 4:1593-1636

Bakkar Y, Nilavongse R, Saha AK (2021) Spillovers of the US real and financial uncertainty on the Euro area. Appl Econ Lett 28:1249-1258

Basu S, Bundick B (2017) Uncertainty shocks in a model of effective demand. Econometrica 85:937-958

Caldara D, Fuentes-Albero C, Gilchrist S, Zakrajšek E (2016) The macroeconomic impact of financial and uncertainty shocks. Eur Econ Rev 88:185-207

Chang Y, Taylor SJ (2003) Information arrivals and intraday exchange rate volatility. J Int Finan Markets Inst Money 13:85-112

Cheng CHJ (2017) Effects of foreign and domestic economic policy uncertainty shocks on South Korea. J Asian Econ 51:1-11

Christiano LJ, Eichenbaum M, Evans CL (1999) Monetary policy shocks: what have we learned and to what end? John B. Taylor and Michael Woodford (Eds.). Handb Macroecon 1:65-148

Christiano LJ, Eichenbaum M, Evans CL (2005) Nominal rigidities and the dynamic effects of a shock to monetary policy. J Polit Econ 113:1-45 
Colombo V (2013) Economic policy uncertainty in the US: does it matter for the euro area? Econ Lett 121:39-42

Dieppe A, Legrand R, Van Roye B (2016) The BEAR toolbox. ECB Working Paper Series 1934, European Central Bank

Dornbusch R (1976) Expectations and exchange rate dynamics. J Polit Econ 84:1161-1176

Jurado K, Ludvigson SC, Ng S (2015) Measuring uncertainty. American Economic Review 105:1177-1216

Justiniano A, Preston B (2010) Monetary policy and uncertainty in an empirical small open-economy model. J Appl Economet 25:93-128

Kido Y (2016) On the link between the US economic policy uncertainty and exchange rates. Econ Lett 144:49-52

Kolasa M, Rubaszek M (2018) Does foreign sector help forecast domestic variables in DSGE models? Int J Forecast 34:809-821

Nilavongse R, Michał R, Uddin GS (2020) Economic policy uncertainty shocks, economic activity, and exchange rate adjustments. Econ Lett 186:108765

Stockhammar P, Österholm P (2016) Effects of US policy uncertainty on Swedish GDP growth. Empirical Economics 50:443-462

Stockhammar P, Österholm P (2017) The impact of US uncertainty shocks on small open economies. Open Econ Rev 28:347-368

Publisher's Note Springer Nature remains neutral with regard to jurisdictional claims in published maps and institutional affiliations. 